\title{
O PRÉ-CAMBRIANO DA REGIÃO DE NATIVIDADE, GO
}

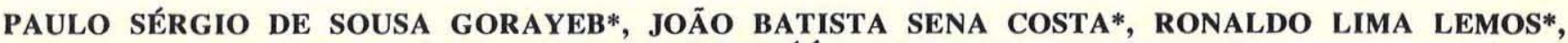 \\ THEODOMIRO GAMA JUNIOR*, RUTH LÉÁ BEMERGUY* e YOCITERU HASUI**
}

\begin{abstract}
THE PRECAMBRIAN OF NATIVIDADE REGION, GOIÁS, BRAZIL. This paper presents the results of the geological investigation performed on the Precambrian rocks at the Natividade region (Northern Goiás). Archean tonalites, mafic rocks, and supracrustals of ancient evolution not yet reconstituted were modified by strong progressive non-coaxial ductile deformation, with displacement, imbrication, shearing, recrytallization in high to medium amphibolite facies, and some migmatization. These modified rocks grade to granite-greenstone terrain in the eastern part of the area. All these modified rocks and unaffected gneisses are assembled in the Goiano Complex. The mass displacement occurred towards SSE and the mylonitic foliation has 0N30 direction, what is interpreted as related to a not yet located oblique ramp. This important tectonic event is admited to be of Late Archean age. Afterwards, high angle ductile shear zones developed, with 10N20 direction, sinistral movement, and recrystallization under greenschist facies conditions. This event seems to be of Early Proterozoic age and introduced modifications on the earlier structural geometry. An ensialic basin could be developed and closed in some interval of the, 1,850-450 Ma period; its sedimentary filling, the Natividade Group, accumulated on stable shelf environment, was folded with $0 \mathrm{~N} 20$ trending axis and slightly transformed by low grade metamorphism. Transcurrent $50 \mathrm{~N} 60$ dextral and $300 \mathrm{~N} 315$ sinistral faults also could form, cutting this supracrustal sequence and the older Goiano Complex.
\end{abstract}

INTRODUÇÃo O Centro de Geociências da Universidade Federal do Pará, por meio de um grupo de pesquisadores, iniciou um programa de investigação em três áreas-chave do Pre-Cambriano no norte de Goiás, que até serviram para treinamento de graduandos do Curso de Geologia em mapeamento geologico básico. Os resultados iniciais referentes às áreas de Porto Nacional e Paraíso do Norte de Goiás foram anteriormente apresentados (Costa $e t$ al. 1982, 1983, 1984, Hasui et al. 1984). A terceira área escolhida foi a de Natividade, com os limites mostrados na figura 1 e cobrindo extensão de $1.600 \mathrm{~km}^{2}$.

Os trabalhos nesta última área foram desenvolvidos em 1983 e apresentados em forma de um relatório (Gorayeb et al. 1984). Este artigo tem em vista a divulgação dos resultados colhidos e elaborados, com o intuito de contribuir para o conhecimento geológico da região.

Os estudos foram realizados em nível de semidetalhe, envolvendo mapeamento litoestrutural em escala de 1:60.000, com a observação de 487 afloramentos e estudo de aproximadamente 400 seções delgadas de amostras coletadas.

TRABALHOS ANTERIORES Existem referências antigas e esparsas a rochas da região de Natividade. As investigaçōes sistemáticas ali realizadas são devidas ao Projeto Leste do Tocantins/Oeste do Rio São Francisco (DNPM/CPRM), cujos resultados finais foram relatados por Costa et al. (1976), e ao Projeto Natividade (DNPM/CPRM) relatado por Correa Filho \& Sá (1980).

O conhecimento acumulado resume-se na identificação e caracterização de dois conjuntos litológicos pré-cambrianos. As rochas gnássicas mais ou menos migmatizadas, com alguns metassedimentos associados, foram atribuídas ao Complexo Goiano (Hasui \& Almeida 1970, Cunha et al. 1981); os metassedimentos de baixo grau foram reunidos na Série Natividade (Moore 1963), depois reclassificada como grupo (Costa et al. 1976). O primeiro é atribuído ao Arqueano, como fazendo parte de terrenos granito-greenstone. $\mathrm{O}$ segundo foi atribuído ao Proterozóico Médio, por suposta correlação com o Grupo Araí, que, por sua vez, é considerado como gerado no Ciclo Uruaçuano.

Com base em dados geocronológicos preliminares tem sido considerada a incidência dos eventos termotectônicos Jequié, Transamazônico, Uruaçuano e Brasiliano na região em que a área se insere (Hasui et al. 1980, Tassinari et al. 1981), faltando informações sobre os efeitos litoestruturais de cada um deles.

GEOLOGIA DA ÁREA O Pré-Cambriano na região de Natividade $e ́$ efetivamente representado pelo Complexo Goiano e pelo Grupo Natividade. O mapa geológico da figura 1 mostra a distribuição dessas unidades na área estudada, bem como as principais estruturas presentes, e o quadro 1 apresenta a ordenação litoestratigráfica.

Estratigrafia COMPLEXO GOIANO No quarto oriental da área, a leste de Riacho do Mato, as rochas desse complexo são gnaisses tonalíticos, que configuram uma estrutura dômica. No núcleo dessa oval, os gnaisses são estruturalmente homogêneos e nas bordas tornam-se bandados, sendo a passagem gradativa e difícil de ser demarcada por falta de afloramentos suficientes.

Os gnaisses bandados são caracterizados pela alternância de faixas granoblásticas quartzo-feldspáticas e faixas lepidonematoblásticas ricas $\mathrm{em}$ biotita e/ou anfibólios, que, localmente, chegam a ser anfibolíticas. Os constituintes principais dessas rochas são quartzo e plagioclásio $\left(\mathrm{An}_{6-10}\right)$, aparecendo anfib́lio, microlínio, biotita, moscovita, clorita e epídoto em quantidades subordinadas. Titanita, apatita, zircão e mineral opaco são outros constituintes menores. O plagioclásio mostra-se intensamente sericitizado. A hornblenda encontra-se alterada parcialmente para tremolita-actinolita e a biotita para clorita.

Os gnaisses homogêneos têm constituição mineralógica análoga à dos bandados, porém a hornblenda aparece em pequena quantidade ou mesmo ausente. Mostram feições de rochas plutônicas, como a textura hipidiomórfica granular, definida por cristais subédricos de plagioclásio e cristais anédricos de quartzo, este último com extinção ondulante moderada a forte. Cristais de tremolita-actinolita, moscovita e clorita são vistos e orientados em vários locais definindo uma foliação discreta.

No restante da área, a oeste de Riacho do Mato, aparecem 


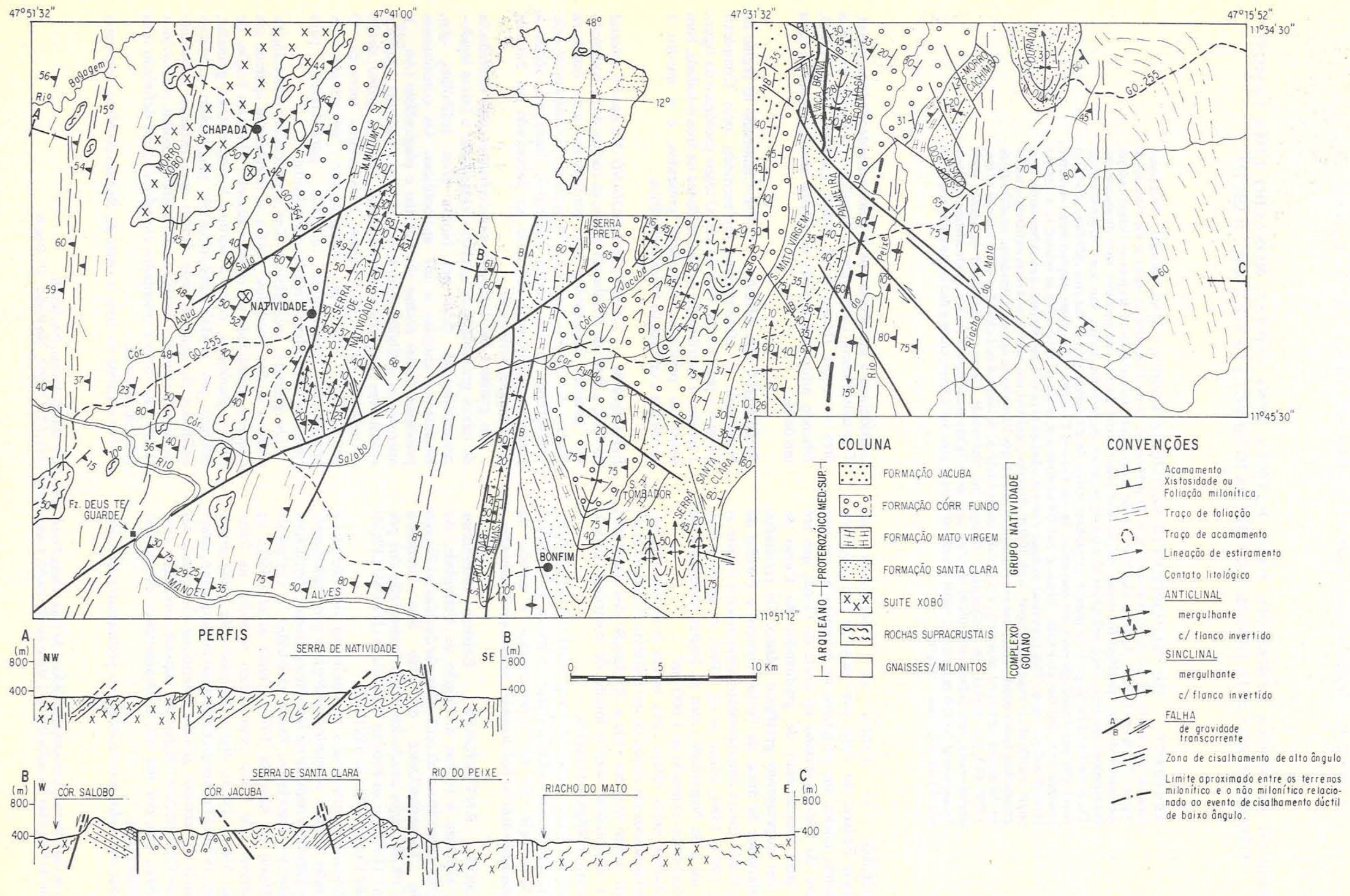




\section{Quadro 1 - Esquema estratigráfico da região de Natividade}

\begin{tabular}{|c|c|c|}
\hline \multirow{4}{*}{ 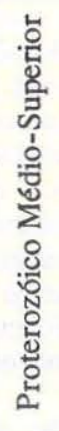 } & Formação Jacuba & $\begin{array}{l}\text { Quartzitos puros e micáceos com níveis arcoseanos restritos, interdigitados com } \\
\text { mármores dolomíticos impuros e filitos. }\end{array}$ \\
\hline & Formação Córrego Fundo & $\begin{array}{l}\text { Quartzitos micáceos na base com níveis conglomeráticos e filitos intercalados, gradando } \\
\text { para filitos e ardósias, no topo, com finos leitos de quartzitos micáceos. }\end{array}$ \\
\hline & Formação Mato Virgem & $\begin{array}{l}\text { Mármores dolomíticos com níveis impuros e leitos pouco expressivos de filitos e } \\
\text { quartzitos micáceos. }\end{array}$ \\
\hline & Formação Santa Clara & $\begin{array}{l}\text { Quartzitos puros e micáceos com estratos cruzados de médio a grande porte, níveis de } \\
\text { metaconglomeráticos polimíticos e filitos intercalados e camadas descontínuas de } \\
\text { mármores dolomíticos. }\end{array}$ \\
\hline \multirow{2}{*}{ ฏ } & Suíte Xobó & $\begin{array}{l}\text { Granitos pegmatóides e pegmatitos graníticos com granada e berilo, diques aplíticos, } \\
\text { normalmente foliados e milonitizados. }\end{array}$ \\
\hline & Complexo Goiano & $\begin{array}{l}\text { Tonalitos, granodioritos, gnaisses tonalíticos, e anfibolitos bandados. Gnaisses miloníticos } \\
\text { e ultramilonitos. Micaxistos com níveis grafitosos, xistos feldspáticos, anfibólio xistos e } \\
\text { gianada quartzitos. }\end{array}$ \\
\hline
\end{tabular}

gnaisses tonalíticos que apresentam feiçöes miloníticas marcantes, com ocelos de plagioclásio e quartzo envolvidos em matriz granoblástica de quartzo, plagioclásio, biotita, hornblenda, microclínio e moscovita (rara). Os ocelos, além de granularização das bordas, apresentam-se internamente desfeitos em subgrãos com contatos poligonais ou de outros tipos. Na matriz, os contatos entre grãos são retilíneos, curvos ou irregulares, sendo freqüentes as feições granoblásticas poligonais em quartzo e plagioclásio. Os grãos de quartzo freqüentemente se distribuem em esteiras configurando microbandas de fluxo que, juntamente com a orientação de minerais placóides e planos de achatamento, configuram uma foliação por vezes até qualificável como laminação. Em função do tamanho dos ocelos, podem ser reconhecidos gnaisses protomiloníticos, miloníticos e ultramiloníticos.

A par do aspecto geral desses gnaisses, eles aparecem com outras feições superimpostas ao longo de zonas de cisalhamento dúctil de alto mergulho. Essas feições são de̊ tipo análogo, decorrentes de granularização, recristalização e recuperação, mas os minerais neoformados sâo sericita, clorita e epídoto, principalmente.

No quarto ocidental da área aparecem, associados aos gnaisses tonalíticos, encraves de micaxistos, granada quartzitos, anfibólio xistos e anfibolitos. Esses encraves têm dimensōes variadas, até quilométricas, formas de lentes e boudins, e dispõem-se em concordância com os gnaisses. Suas rochas também apresentam foliação milonítica paralela à dos gnaisses.

Os micaxistos podem ser observados principalmente ao longo das rodovias GO-255, entre Natividade e Goianorte, e GO-364, entre Natividade e Chapada. Têm granulaçảo média a grossa. e são constituídos de quartzo, moscovita, biotita e clorita, além de pequenas quantidades de plagioclásio, granada, apatita, zircão, epídoto, turmalina e mineral opaco.

Os quartzitos são vistos apenas na porção sudoeste da área, nas adjacências da Fazenda Deus-Te-Guarde. Têm granulação média e são constituídos de quartzo, granada e mineral opaco.

Os anfib́́lio xistos ocorrem associados aos micaxistos, sendo constituídos de actinolita, tremolita, talco, clorita, plagioclásio e quartzo. Em algumas partes aparece epídoto até em grandes quantidades.

Os corpos de anfibolito aparecem em meio aos gnaisses e são constituídos de hornblenda, plagioclásio e quartzo, e pequenas quantidades de granada, epídoto, apatita, titanita, zircão e mineral opaco.

Do conjunto de gnaisses, um corpo particular se destaca na parte noroeste da área. Ele tem forma irregular, com 14 × 5 $\mathrm{km}$, alongado na direção NNE, e é constituído de gnaisses de granulação média a muito grossa, marcados por uma foliação milonítica concordante com a regional. Os gnaisses são constituídos de quartzo, microclínio, plagioclásio, moscovita e biotita, estando presentes ainda turmalina, berilo e granada em quantidades menores e, acessoriamente, epídoto, apatita, zircão, carbonato e mineral opaco. Xenólitos das encaixantes são observados nas bordas do corpo. Veios aplíticos e pegmatíticos relacionados a essas rochas acham-se alojados nos xistos e gnaisses adjacentes. Esse conjunto de rochas é enfeixado na Suíte Xob6, nome emprestado do morro homônimo, um dos que se destacam na morraria sustentada por elas e em que se expöem as variedades petrográficas.

Com freqüência, em todos os litotipos referidos podem ser observados neossomas/leucossomas gerando tipos variados de migmatitos. Os mobilizados quartzo-feldspáticos podem ter granulação fina a muito grossa. $\mathrm{Na}$ maior parte são concordantes e exibem feiçōes de gnaissificação, estricção e boudinage relacionadas com o processo de milonitização, mas uma parte é discordante e indeformada.

GRUPO NATIVIDADE O Grupo Natividade está bem representado na área, sustentando serras de orientação NNE com altitudes máximas de $850 \mathrm{~m}$, a exemplo das serras de Natividade, Santa Clara, Vaca Brava, Palmeira e Formosa, onde existem excelentes exposiçōes. Assenta-se sobre rochas do Complexo Goiano por uma discordância angular e erosiva, mas contatos tectônicos também são verificados.

O empilhamento litoestratigráfico definido é mostrado na seção colunar esquemática da figura 2 e a distribuição das unidades é vista no mapa geológico da figura 1. O Grupo Natividade foi dividido em quatro formações, nomeadas Santa Clara, Mato Virgem, Córrego Fundo e Jacuba, da base para o topo. Essas formações foram inicialmente reconhecidas nos trabalhos do Projeto Natividade-Almas, relatado por Gorayeb et al. (1984) e são aqui definidas de acordo com o Código Brasileiro de Nomenclatura Estratigráfica e Guia de Nomenclatura Estratigráfica (CENE/SBG 1986).

Formação Santa Clara A Formação Santa Clara tem sua seção-tipo na serra homônima e na Serra de Natividade, onde há excelentes exposiçōes de seus constituintes litológicos. Na área da Serra de Natividade, a seção-tipo pode ser descrita ao longo do córrego que abastece a cidade ou da estrada que leva à antena retransmissora de televisão, onde se 
expõe continuamente um pacote de quartzitos puros com intercalações descontínuas de metaconglomerados polimíticos, passando para quartzitos micáceos em direção ao topo. Nesta regiăo, as rochas estão dobradas isoclinalmente com os planos axiais tombados para leste. A oeste, está em contato, por provável falha que não foi possível caracterizar, com filitos da Formação Corrego Fundo e, a norte, faz limite com os mármores da Formação Mato Virgem por contatos concordantes e graduais. A leste está em contato por falha com os gnaisses do Complexo Goiano.

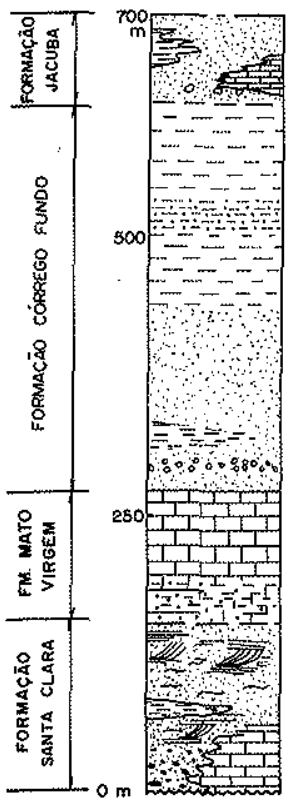

Quartzitos puros e micáceos com niveis arcoseanos restritos interdigitados com mármores dolomíticos impuros $b$ filitos.

Filitos a ardósias com finos leitos de quart ziłos micáceos.

Quartzitos micóceos com niveis conglomeratlcos a finos leitos de filltos.

Mórmores dolomiticos com niveis impuros $\theta$ finos leltos de quarfzltos micáceos e filitos.

Quartzitos puros e micóceos, com estratos cry zodos de médlo a grande porte, niveis de meta conglomerados polimítlcos, filltos a camadas descontínuas de mármores dolomíticos.

Figura 2 - Seção colunar do Grupo Natividade na região de Natividade-Almas

$\mathrm{Na}$ porção centro-sul da área, na Serra de Santa Clara, bem como nas regiões adjacentes, pelas serras da Palmeira, Formosa e Vaca Brava, e dos morros Saco dos Bois, do Cachimbo e da Onça, podem ser descritas as seçōes mais completas desta formação. Alí aparece um espesso e contínuo pacote de orientação NNE com mergulhos médios de $45^{\circ}$ para oeste, que se fecha em amplo sinclinal em direção ao sul da área, próximo ao povoado Bonfim. Assentando-se discordantemente sobre rochas gnáissicas do Complexo Goiano, aflora de leste para oeste uma seqüencia de quartzitos puros com niveis de metaconglomerados polimíticos e quartzitos conglomeráticos na base, com lentes de filitos, seguidos por quartzitos predominantemente micáceos para o topo. Camadas descontínuas de mármore ocorrem na base do pacote e o melhor registro está na Serra da Palmeira, onde, a leste, faz contato direto com gnaisses e a oeste e sul, grada para quartzitos. Nos morros da Onça, Saco dos Bois e do Cachimbo situação semelhante pode ser descrita, mas nesta regiăo aparecem camadas isoladas por falhas ou por erosão diferencial em meio aos gnaisses.

A Formaçâo Santa Clara, portanto, compreende um pacote de quartzitos puros na base, passando a micáceos com intercalaçöes descontínuas de metaconglomerados polimíticos, mármores dolomíticos, filitos e quartzitos. com cianita e cloritóide. Feições primárias estáo bem preservadas, como marcas de onda e estratificaçōes gradual, plano-paralela e cruzada, esta altima de portes médio e grande. A espessura é de aproximadamente $150 \mathrm{~m}$.

Os quartzitos puros apresentam textura granoblástica com granulaçăo fina uniforme ou seriada. Os grãos detríticos de quartzo săo angulosos e subarredondados e estão envolvidos por grấos de quartzo mais finos; mostram-se deformados (fraturados, com forte extinção ondulante e às vezes achatados paralelamente à foliação) e pouco recristalizados.

Os quartzitos micáceos, que são os termos predominantes, exibem textura grano-lepidoblástica e lepidoblástica, com grãos maiores de quartzo, por vezes ainda mostrando seu caráter detrítico, e matriz mais fina de quartzo e moscovita. $O$ acamamento $\varepsilon$ denunciado por níveis milimétricos ricos em moscovita que se alternam com aqueles mais ricos em quartzo.

Os metaconglomerados formam intercalaçóes de espessuras decimétricas e métricas. São polimíticos contendo seixos de 1 a $30 \mathrm{~cm}$ de quartzo, quartzito puro, quartzito turmalinífero, turmalina e granito, em matriz de quartzo e micas, ocasionalmente incluindo feldspato e clorita. As formas dos seixos são elipsoidais com plano de achatamento concordante com a xistosidade.

Os mármores dolomíticos ocorrem como camadas de espessuras variadas. Têm cor cinza, são maciços e se mostram constituídos de dolomita e pequenas proporções de quartzo, flogopita, plagioclásio e mineral opaco. Gradam lateral e verticalmente para os quartzitos puros e micáceos, tornando-se impuros na zona de passagem mediante aumento nas quantidades de quartzo, flogopita e plagioclásio. É comum intenso fraturamento com preenchimento de vênulas de quartzo e calcita. Também a dissolução superficial permitiu a formação de grutas, até expressivas.

Os filitos têm textura lepidoblástica dada pela sericita. Outros constituintes são mineral opaco, quartzo, plagioclásio, clorita e turmalina, todos em pequenas quantidades. Localmente, na extremidade norte da Serra de Natividade, aparecem quartzitos com cloritoide e cianita, intercalados em quartzitos puros e representando níveis mais aluminosos.

Ao longo de zonas de falha aparecem quartzitos mostrando agregados de quartzo muito estirados com textura ribbon e forte extinção ondulante. Moscovita e mineral opaco associam-se a esses agregados orientando-se segundo a foliação desenvolvida.

Formação Mato Virgem Esta formaçăo está bem exposta na serra homônima assim como na Serra do Tombador, onde foi definida sua seção-tipo. A Serra do Mato Virgem, com altitudes aproximadas de $500 \mathrm{~m}$, destaca-se por sua morfologia caracterizada por cristas angulosas de mármores, com vegetação rala do topo. A norte e a sul da área-tipo, esta unidade pode ser seguida com maior ou menor dificuldade, em áreas planas, por afloramentos esparsos ou por seu solo marrom-avermelhado. Ao longo da GO-255, entre Natividade e Almas, a sul da Serra do Mato Virgem, também afloram as rochas desta unidade. A Serra Preta e o Morro do Mutum são ainda exemplos de ocorrências rochosas desta unidade. Ela ocorre dominantemente na porção central da área, onde define uma camada contínua com espessura aproximada de $120 \mathrm{~m}$. Repousa concordantemente sobre os quartzitos da Formação Santa Clara, com passagem que se dá de forma gradativa, marcada por finas intercalações de quatzitos e filitos na base do pacote. Na parte oeste da área, bem como na porção centro-norte, esta formação está ausente de tal forma que as rochas da Formação Santa Clara estão em contato direto com as rochas da Formação Córrego Fundo; no restante da área as relaçōes entre as três formaçōes são normais.

É constituída essencialmente de mármores dolomíticos com intercalações de filitos e quartzitos micáceos na base. Os mármores dolomíticos são geralmente maciços, localmente exibindo estratificação e/ou foliação. Têm textura granoblástica dada por cristais de dolomita. Em pequanas quantidades aparecem flogopita, quartzo, clorita, turmalina e mineral opaco. Nos termos impuros comparecem também microclínio e plagioclásio. E sempre proeminente o fraturamento e preenchimento por vênulas de calcita $\mathrm{e}$ quartzo. A foliação, quando desenvolvida, é dada por cristais alongados de dolomita e palhetas de flogopita. Também, em 
termos finos, ocasionalmente são vistos estilolitos.

Formação Córrego Fundo Esta formação tem sua seção mais completa nas adjacências do Córrego Fundo, na porção central da área. Ao longo da rodovia GO-255, no trecho entre Natividade e Almas, e, respectivamente, a leste e oeste das serras Vaca Brava e Natividade, registraram-se as melhores exposições, onde geralmente constituem áreas planas. Em seções paralelas ao Córrego Fundo, a seqüência inicia com quartzitos passando para filitos e ardósias, com delgados leitos de metapelitos grafitosos e hematíticos, e quartzitos micáceos em direção ao topo. O pacote, de espessura aproximada de $350 \mathrm{~m}$, recobre concordantemente a Formação Mato Virgem. $\mathrm{Na}$ região adjacente à cidade de Natividade e na porção centro-norte, esta formação faz contato por prováveis falhas com a Formação Santa Clara.

Os quartzitos definem um pacote contínuo geralmente bem estratificado. São formados por quartzo e pequenas quantidades de sericita, turmalina, zircão e mineral opaco. Texturalmente, observam-se grãos maiores de quartzo de 0,5 a $1,0 \mathrm{~mm}$, subarredondados e fraturados, ou achatados e recristalizados nas bordas, delineando feiçőes mortar; eles estão imersos em matriz fina, granoblástica, de quartzo e mica, esta ligeiramente orientada.

Filitos e ardósias mostram textura lepidoblástica dada pela orientação preferencial de sericita e clorita. Quartzo e mineral opaco sảo os outros constituintes de tais rochas. O acamamento preservado se destaca pela variação das quantidades de quartzo, que diminui da base para o topo e pela presença de níveis quartzosos intercalados, sucessivamente.

Formação Jacuba Esta formação ocorre ao longo do Córrego do Jacuba e nas serras adjacentes orientadas na direção NNE e com altitudes máximas de $700 \mathrm{~m}$. É constituída, na base, por quartzitos puros e micáceos, com níveis arcoseanos, gradando lateral e verticalmente para quartzitos arcoseanos, filitos e mármores alternados. Esse conjunto se acha dobrado em anticlinais e sinclinais orientados na direção $10 \mathrm{~N} 20$. Sua espessura aproximada é de $75 \mathrm{~m}$, mas é possível que valores maiores existam mais a norte, onde a unidade adquire maior expressão. Esta unidade recobre concordantemente a Formação Córrego Fundo.

Os quartzitos apresentam grãos detríticos maiores de quartzo (de 0,4 a $1,5 \mathrm{~mm}$ ), que se mostram fraturados, com forte extinção ondulante e com as bordas cominuídas e recristalizadas (mortar), imersos em matriz mais fina $(0,05 \mathrm{~mm}$ em média) de quartzo e alguma sericita. Marcas de onda e estratificação plano-paralela estão preservadas e, por vezes, vê-se foliação incipiente superposta.

Os metarcóseos são finos, maciços e mostram textura granoblástica eqüigranular. Grãos de quartzo, microclínio e plagioclásio, com películas ferruginosas envoltórias, são os constituintes; sericita, mineral opaco, carbonato, zircão e turmalina aparecem em pequenas quantidades.

Os mármores dolomíticos impuros têm textura granoblástica e são constituídos de dolomita, quartzo, microclínio, plagioclásio, flogopita, clorita e algum mineral opaco. Preservam estratificação plano-paralela e freqüentemente exibem fraturamento e preenchimento por vênulas irregulares de calcita e quartzo.

Os filitos têm textura lepidoblástica dada por sericita e clorita. Quartzo é o outro constituinte da rocha, formando agregados e exibindo extinção ondulante.

Estruturas COMPLEXO GOIANO No Complexo Goiano são mais importantes três tipos de estruturas.

$\mathrm{O}$ primeiro corresponde à estrutura dômica referida acima. Ela tem forma elíptica em planta, com cerca de $10 \times 18 \mathrm{~km}$ e eixo maior orientado segundo NNW. Esse tipo de feição foi reconhecido como repetitivo do quarto oriental da área para leste, até a região de Dianópolis, configurando-se uma regiâo de ovais gnáissicas, entre as quais aparecem seqüências vulcano-sedimentares do tipo greenstone belt (Costa et al. 1976, Correa Filho \& Sá 1980, Costa 1985).

O segundo tipo aparece do vale do Riacho do Mato para oeste, afetando todas as rochas gnáissicas, supracrustais e a Suíte Xob6, com proeminência crescente de leste para oeste. Trata-se da foliação milonítica $\mathrm{C}$, que apresenta direção $\mathrm{N}$ 0-30, com mergulhos baixos a altos, voltados principalmente para o quadrante NW. Sua atitude pode ser tomada como a do plano XY (planos dos eixos cinemátices de maior estiramento e intermediário). As variações de direção e mergulho estão relacionadas a ondulações superimpostas, à adaptação da foliação em torno das lentes e boudins em que se acham desmembradas as rochas e principalmente a cisalhamentos não-coaxiais de tipo transcorrente. Essa foliação envolve planos de fluxo milonítico, orientação de minerais ou agregados minerais por rotação mecânica, ou recristalização, aleitamento, bandamento tectônico produzido por dissolução por pressão e feições planares com relaçōes do tipo S x C (Berthé et al. 1979, Lister \& Snoke 1984). Também aparecem ondulações, dobras intrafoliais e dobras em bainha de orientações inconstantes; elas são ocasionais e solitárias, desfazendo-se nos rumos dos ápices e núcleos.

No plano da foliação milonítica referida desenvolveu-se uma lineação de estiramento, proeminente em tectonitos $\mathrm{L}$ e incipiente ou indistinguível naqueles de tipo S. Sua orientação preferencial é NNW-SSE, com variaçöes para NW-SE; essa atitude geral pode ser tomada como a orientação de $\mathrm{X}$ (eixo maior de estiramento) do evento de deformação que produziu essas feições. $\mathrm{O}$ escoamento de massas deu-se no rumo SSE e a envergadura do processo está refletida no desmembramento, transporte e imbricação dos litotipos.

A deformação foi acompanhada de transformaçőes mineralogicas em condiçōes de fáceis anfibolito média a alta, possibilitando a incidência de migmatização e ao que parece até formação de granitóides sintectônicos (Suíte Xobó). Paragêneses em desequilíbrio são freqüentes, podendo ser relacionadas a retrometamorfismo durante o arrefecimento.

O terceiro tipo de estrutura corresponde a zonas de cisalhamento dúctil, transcorrentes, de alto mergulho. Elas podem ser de portes variados, das quais as maiores se acham indicadas no mapa da figura 1 , afetando o Complexo Goiano quer no domínio milonitizado, quer no domínio das ovais. Essas zonas de cisalhamento são sinistrais, de direçōes 10N20, com larguras de até $2 \mathrm{~km}$. Ao longo delas, as rochas exibem feiçōes decorrentes de deformação dúctil não-coaxial, estando a foliação $\mathrm{C}$ em posição subvertical, a lineação de estiramento sendo sub-horizontal e a recristalização tendo ocorrido em condições de fáceis xisto verde. Os deslocamentos desfiguraram profundamente o quadro estrutural imprimido pelo evento tectônico anterior.

GRUPO NATIVIDADE Os metassedimentos do Grupo Natividade apresentam dobras desenhadas pelo acamamento reliquiar, sin-metamórficas, de dimensōes centimétricas a decaquilométricas, com planos axiais de direção 0 N20 e eixos de baixo mergulho geralmente voltado para o lado norte. Associam-se a essas dobras xistosidade ou clivagem ardosiana plano-axial nos metapelitos ou clivagem de fratura em leque nos quartzitos e mármores. Nos metaconglomerados, o plano de achatamento de seixos tem relação plano-paralela ou em leque com as dobras, e os eixos de estiramento são paralelos aos eixos das mesmas.

$\mathrm{Na}$ região da Serra de Natividade (porção ocidental do grupo), as dobras são fechadas a isoclinais, os ápices são ligeiramente espessados e os planos axiais mergulham cerca de $60^{\circ}$ para o lado oeste. As dobras são assimétricas, em Z (olhando de sul para norte); os flancos curtos com maior freqüência estão invertidos, chegando até a serem segmentados.

No restante da área do Grupo Natividade, as dobras 
apresentam planos axiais subverticais e variam de isoclinais a oeste para suaves a leste.

Além dessas dobras, observam-se nos metapelitos intercalados em quartzitos a presença de crenulação e clivagem de crenulação, que não modificam a geometria geral acima descrita. Também aparecem juntas, principalmente perpendiculares aos eixos das dobras.

Acompanhando os eventos de deformação, impuseram-se transformaçōes mineralogicas em condiçőes de fácies xisto verde baixa. Localmente, na porção norte da Serra de Natividade, existe uma associação com cloritóide, cianita e quartzo em rochas quartzíticas extremamente deformadas, sugerindo condições mạis altas de metamorfismo, especialmente em relação à pressão.

FALHAS. As falhas que seccionam as rochas da área são reunidas em dois grupos.

$O$ primeiro reúne as falhas transcorrentes dextrais de direção 50 N60 e sinistrais de direção 300N315 (Fig.1), que seccionam o Complexo Goiano e o Grupo Natividade. Elas são marcadas por fragmentação, forte extinção ondulante de minerais, kinks em micas e outras feições que caracterizam proto a ultracataclasitos. Alcançam $35 \mathrm{~km}$ de extensão e o encurvamento de feições estruturais pretéritas permite deduzir seu movimento relativo. A mais expressiva 6 a que da porção central se dirige para o canto sudoeste da área: ela tem rejeito da ordem de $2 \mathrm{~km}$, limita ao sul a faixa ocidental da Formação Santa Clara e condiciona forte desvio do Rio Manoel Alves.

As falhas sinistrais chegam a ter $24 \mathrm{~km}$ de extensão e algumas delas truncam falhas dextrais. $O$ rejeito máximo estimado e da ordem de $1 \mathrm{~km}$.

Considerando a idade pós-Natividade, as direções e os movimentos relativos dessas falhas, pode-se inferir que elas sejam produtos de um sistema de tensão com o eixo principal de compressão orientado aproximadamente segundo $\mathrm{E}-\mathrm{W}$.

$O$ outro grupo de falhas reúne as de caráter normal. Elas têm direçóes $\mathrm{N}-\mathrm{S}$, NNE e NNW, envolvendo rejeitos de até $300 \mathrm{~m}$, que geraram alguns horstes e grábens e blocos basculados. Tais falhas, por afetarem também a Bacia do Parnaíba mais a norte, são atribuídas ao Evento Sul-Atlântiano (ou Reativação Wealdeniana), ativa durante o Jurássico na região.

EVOLUÇÃo GEOLÓGICA Os dados acima apresentados permitem delinear a evolução geologica em termos das seguintes etapas sucessivas:

1. Desenvolvimento das rochas tonalíticas, básicas e supracrustais, em uma história antiga que ainda resta por se reconstituir. Uma delas, na região de Almas-Dianópolis, guarda ainda feiçöes que a caracterizam como conjuntos granito-greenstone.
2. Incidência do processo de deformação não-coaxial, envolvendo deslocamento de massas rochosas para SSE e impondo-lhes foliação milonítica de direção $30 \mathrm{~N}$ e lineação de estiramento NNWmSSE, o que implica rampa obliqua, produzindo desmembramento, transporte, imbricações $\mathrm{e}$ milonitização, bem como recristalização em condiçöes de fácies anfibolito média a alta, chegando atê à remobilização quartzo-feldspática (migmatitos, Suíte Xob6). Paragêneses em desequilíbrio podem ser relacionadas com arrefecimento. As rochas resultantes, afetadas ou não pela referida deformação, são enfeixadas no Complexo Goiano.

3. Incidencia do processo de transcorrência dúctil, gerando zonas miloníticas de alto mergulho, com deslocamentos sinistrais e acarretando recristalização das rochas envolvidas em condiçöes de fácies xisto verde. Os movimentos foram importantes, impondo mudanças geométricas sensíveis no quadro estrutural.

4. Desenvolvimento do Grupo Natividade, em bacia ensiálica, a cuja cerragem se relacionam o dobramento simples e o metamorfismo de baixo grau.

5. Incidencia de falhas transcorrentes dextrais $50 \mathrm{~N} 60$ e sinistrais $300 \mathrm{~N} 315$, aparentemente envolvendo tensăo compressiva principal E-W.

6. Incidência de falhas normais N-S, NNE e NNW durante a Reativação Sul-Atlântica.

Quanto à idade absoluta, o elemento referencial de que se dispốe é dado pelos granitos da Suíte Lajeado. (Costa et al. 1984). Estes, na regiấo de Porto Nacional, constituem corpos intrusivos no Complexo Goiano, não estão afetados por deformação dúctil, acham-se encobertos pelo Grupo Natividade e foram datados em $1870 \mathrm{Ma}$ (Costa 1985). Isso permite considerar os processos dos itens 2 e 3 como anteriores aquela idade e, sendo o Jequié e o Transamazônico os dois eventos termotectônicos mais antigos regionalmente, podemos vincula-los a estes. O Complexo Goiano fica, desse modo, situado no Arqueano, como é correntemente aceito.

Quanto ao Grupo Natividade e às falhas transcorrentes, o limite mínimo de idade é o Cambro-Ordoviciano, isto é, o fim do Evento Brasiliano. Isso deixa em aberto amplo intervalo de tempo entre 1870 e $450 \mathrm{Ma}$, durante o qual tais feiçöes se formaram, não se dispondo de elementos seguros na área estudada para definir idades precisas.

Agradecimentos Os autores expressam seus agradecimentos à Companhia Vale do Rio Doce, pelo suporte financeiro à realização da presente investigação, bem como aos estudantes da disciplina Estágio de Campo III do Curso de Geologia da UFPA, que, em 1983, participaram com entusiasmo e dedicação dos trabalhos na área. Igualmente, registram agradecimentos ao Instituto de Pesquisas Tecnologicas do Estado de São Paulo, pela permissão a um dos autores para que pudesse participar da pesquisa.

\section{REFERÉNCIAS BIBLIOGRÁFICAS}

BERTHÉ, D.; CHOUKROUNE, P.; GAPAIS, D. 1979. Orientations preferentielles du quartz et orthogneissification progressive en régime cisaillant: un exemple da cisaillement sud-armoricain. Bull. Mineral., 102:265-272.

CENE/SBG-COMISSÄO ESPECIAL DE NOMENCLATURA ESTRATIGRÁFICA/SBG. 1986. Código Brasileiro de Nomenclatura Estratigráfica e Guia de Nomenclatura Estratigráfica. Rev. Bras, Geoc., 16:(4):370-415.

CORREA FILHO, F.C.L. \& SA, A.M. 1980. Projeto Natividade; Goiânia, conv. DNPM/CPRM. (Relatório final, inédito).

COSTA, J.B.S. 1985. Aspectos litoestruturais e evolução crustal da regiäo centro-norte de Goias. Belém. $210 \mathrm{p}$. (Tese de Doutoramento, CG-UFPA)

COSTA, J.B.S.; GORAYEB, P.S. de S.; BEMERGUY, R.L.; GAMA Jr,, T.; KOTSCHOUBEY, B.; LEMOS, R.L. 1983. Projeto Paratso do Norte, Goiás. Belém, Conv, CVRD/UFPA 125p. (Relatório inédito)

COSTA, J.B.S.; LEMOS, R.L.; MARTINS, J.P. de A,; BELTRÄO,
J.F.; GÓES, A.M., HASU1, Y. 1984. Geologia da região de Porto Nacional, GO. Rev. Bras. Geoc., 14(1):3-11.

COSTA, J.B.S.; MARTINS, J.P. de A.; BELTRÃO, J.F,; GÓES, A.M.; LEMOS, R.L.; GORAYEB, P.S. de S. 1982. Projeto Porto Nacional. Belem, Conv. DNPM/UFPA. 104 p. (Relatório inédito)

COSTA, L.A.M. da ; PORTELA, A.C.; NILSON, A.A. PALE, C.R.O., MARCHETTO, L.M.; SANTOS, E.L. dos; MENEGHESSO, G.; INDA, H.A.V.; STERNA, R.; MARCHETTO, M. BAPTISTA, M.B.; FRATIN, O.; MOSMHANN, R.; OLIVEIRA, T.F.D.; SILVA, W.E. de. 1976. Projeto Leste do Tocantins, Oeste do Rio Sáo Francisco. Rio de Janeiro, Conv. DNPM/CPRM/ PROPESC. (Relatório final inédito)

CUNHA, B.C.C. da; POTIGUAR, L.A.T.; IANHEZ, A.C.; BEZERRA, P.E.L.; PITTHAN, J.H.L.; SOUZA Jr.; J.J. de; MONTALVÁR, R.M.G. de; SÓUZA, A.M.S. de; HILLDRED, P.R.; TASSINÁRI, C.C.G. 1981. Geologia. In: MME-Projeto Radambrasil, Folha SC. 22 - Tocantins. Levantamento de Recursos Naturais. Rio de Janeiro. v. 22-21-196. 
GORAYEB, P.S. de S.; COSTA; J.B.S.; LEMOS, R.L.; BEMERGUY, R.L.; GAMA Jr.; T.; KOTSCHOUBEY, B. 1984. Projeto Natividade-Almas. Belém. Conv. CVRD/UFPA. (Relatório inédito)

HASUI, Y, \& ALMEIDA, F.F.M. DE. 1970. Geocronologia do Centro-Oeste brasileiro. Bol. Soc. Bras. Geol., 19:5-26.

HASUI, Y.; COSTA, J.B.S.; GORAYEB, P.S. de S.; LEMOS. R.L.; GAMA Jr., T.; BEMERGUY, R.L. 1984. Geologıa do PréCambriano da regiâo de Paraíso do Norte de Goiás. In: CONGR. BRAS. GEOL., 33, Rio de Janeiro, 1984. Anais... Rio de Janeiro, SBG. v. 5, p. 2220-2233.

HASUI, Y.; TASSINARI, C.C.G.; SIGA Jr, O.; TEIXEIRA, W; ALMEIDA, F.F.M. de, KAWASHITA, K. 1980. Idades Rb-Sr e $\mathrm{K}-\mathrm{Ar}$ do Centro-Oeste brasileiro e seu significado geológico-geotectônico, In: CONGR. BRAS. GEOL., 31, Baln. Camboriú, 1980. Anais... Baln. Camboriú, SBG. v. 5 p.
2659-2676.

LISTER, G.S. \& SNOKE, A.W. 1984. S-C Mylonites. J. Struct. Geol., 6:617-638.

MOORE, B. 1963. Geologic reconnaissance of the southwest corner of the Maranhāo Basin. Rio de Janeiro, Depex/Petrobrás. (Relatório 1954 , inédito)

TASSINARI, C.C.G.; SIGA Jr., O.; TEIXEIRA, W. 1981. Panorama geocronologico do Centro-Oeste brasileiro: soluçōes, problemática e sugestōes. In: SIMP. GEOL. DO CENTRO-OESTE, 1 Goiânia, 1981. Atas... Goiânia, SBG. p. 93-116.

MANUSCRITO 490

Recebido em 19 de janeiro de 1988 Revisão aceita em 25 de maio de 1988

\section{NOTÍCIAS}

\section{DIA DO CIENTISTA - 23 DE SETEMBRO}

A Diretoria da SBPC informa que está promovendo o lançamento do Dia do Cientista a 23/09, que coincide com o início da primavera entre nós. A decisão, tomada em assembléia geral da Sociedade, simboliza o exercício de uma atividade de pesquisa voltada para a Natureza e para o que é antes de tudo um ato de criação; renovação e de descoberta. O papel do cientista é, sem dúvida, da mais ampla relevância e exige, daqueles que o exercem, a dedicação completa aos avanços do conhecimento. Nesse sentido, todos os dias são dias do labor científico, mas julgou-se conveniente fixar um dia especial para se refletir sobre as funçōes da ciência na sociedade moderna. Qualquer que seja a forma de se comemorar o Dia do Cientista, torna-se essencial que seja destacada a sua resporsabilidade social, no sentido de conhecer tanto quanto preservar a natureza, bem como desvendar os processos vitais e a própria capacidade mental no exercício do conhecimento. Além de que se abrem perspectivas para uma melhor qualidade de vida e para que se venha a proporcionar a todas as pessoas os benefícios do conhecimento científico. Embora a elaboração do conhecimento seja uma ação individual, ela só se torna possível e se socializa como produto de açōes coletivas, que compöem o cotidiano na vida nos laboratórios, nas salas das universidades, e nos gabinetes dos institutos de pesquisa. Mas é na discussão em congressos e seminários e no âmbito das sociedades científicas que se dâo o intercâmbio e a fecundação de idéias e quando o trabalho científico é submetido ao teste da validação coletiva e posto a serviço da Sociedade que, afinal de contas, sustenta o trabalho do cientista. (Informe Ciência Hoje, (149), 24 a 30 de setembro de 1988.)

\section{EROSÃO ACELERADA NO VALE DO RIO DAS MORTES}

Cerca de $5 \%$ da área total de 6.606 quilômetros quadrados da bacia do Rio das Mortes (sul de Minas), afluente do Rio Grande, já estão diretamente comprometidos por processo de erosâo acelerada, segundo diagnóstico ambiental elaborado pelo setor de recursos minerais da Fundação Centro Tecnológico de Minas Gerais (Cetec). O coordenador do projeto, geólogo Marcus Mello, estima que o índice é dez vezes maior do que o tolerável. Erosões do tipo voçoroca podem ser identificadas na área por imagens de satélite. De acordo com o relatório do Cetec, a erosão é provocada principalmente por obras da Ferrovia do Aço, mineração executada pela empresa Mibra, garimpo ilegal e pisoteamento de gado. $\mathrm{O}$ assoreamento do rio tem provocado a redução da capacidade de águas da represa de Furnas. Se não forem adotadas medidas corretivas imediatas, alerta o geólogo, a bacia do Rio das Mortes poderá ficar irremediavelmente comprometida num prazo máximo de dez anos. Informe Ciência Hoje, (149).

É indispensável que os homens consigam preservar outra coisa além daquilo que lhes serve para fazer solas de sapatos ou máquinas de costura; $\varepsilon$ indispensável que estabeleçam uma reserva onde possam se refugiar de vez em quando. Só então se poderá falar de uma civílização. 